\title{
Life after disturbance (I): changes in the spatial genetic structure of Jacaranda copaia (Aubl.) D. Don (Bignonianceae) after logging in an intensively studied plot in French Guiana
}

\author{
Thomas Leclerc • Ruppert Vimal • Valérie Troispoux • \\ Sophie Périgon • Ivan Scotti
}

Received: 2 May 2014 / Accepted: 21 January 2015 /Published online: 13 February 2015

(C) INRA and Springer-Verlag France 2015

\begin{abstract}
- Key message Forest disturbance affects the withinpopulation distribution of genetic diversity, but not its overall levels, in a tropical pioneer tree species. In particular, clumps of related saplings with impoverished diversity are found in canopy gaps but not under forest cover. - Context Forest disturbances can have long-term consequences on the genetic structure of tree populations, because they can alter the demographic properties of the regeneration
\end{abstract}

\section{Handling Editor: Ricardo Alia \\ Contribution of the co-authors TL analysed data; RV collected samples and data, ran data analyses and wrote the paper; VT and SG collected and cured data; IS conceived the experiment, ran data analyses and wrote the manuscript. \\ Thomas Leclerc tragically deceased in a car accident during his internship in French Guiana while carrying out this research. The remaining authors completed the study and wrote the manuscript on his behalf. This paper is dedicated to his memory and to his family and friends.}

Electronic supplementary material The online version of this article (doi:10.1007/s13595-015-0462-0) contains supplementary material, which is available to authorized users.

\section{T. Leclerc}

École Nationale Supérieure Agronomique de Rennes,

Rennes, France

\section{R. Vimal}

Université des Antilles et de la Guyane, Campus Agronomique, 97310 Kourou, French Guiana

e-mail: ruppert.vimal@gmail.com

V. Troispoux $\cdot \mathrm{S}$. Périgon $\cdot$ I. Scotti

INRA, Unité mixte de recherche 0745 « Ecologie des Forêts de

Guyane » (EcoFoG), BP 709, 97387 Kourou, French Guiana

\section{Troispoux}

e-mail: valerie.troispoux@ecofog.gf

S. Périgon

e-mail: sophie.perigon@gmail.com process and favour some subpopulations/genotypes, both by stochastic processes and by selection. Intermediate disturbances tend to favour species diversity, at least in highly diverse communities, but their effect on intra-specific diversity is unknown. - Aims In this study, we have looked at the genetic consequences of forest disturbance in a stand of the long-lived Neotropical pioneer species, Jacaranda copaia.

- Methods The study site was experimentally logged in 1984, and the canopy gaps generated by the logging were mapped. Seedlings of $J$. copaia colonised the gaps, as expected, at a higher density than in the surrounding forest. In 2006, we exhaustively sampled all saplings and adult trees available in a 25-ha area. The samples were genotyped at nine microsatellite loci, and the distribution of genetic diversity was inspected by analyses of spatial autocorrelation, automated Bayesian assignment and comparisons of diversity between cohorts by bootstrap (RaBoT).

- Results Spatial autocorrelation was found to extend farther in post-disturbance saplings than in the undisturbed population (100 $\mathrm{m}$ and beyond versus less than $50 \mathrm{~m}$ ), and divergent clumps $\left(F_{\mathrm{ST}}=0.05\right)$ of related genotypes were found; genetic

Present Address:

R. Vimal

10 rue des Loriots, 34000 Montpellier, France

Present Address:

S. Périgon

CNRS, Unité Mixte de Recherche 5553 « Laboratoire d'Écologie

Alpine » (LECA), 2233 Rue de la Piscine, 38400 Grenoble, France

Present Address:

I. Scotti $(\square)$

INRA, URFM « Ecologie des Forêts Méditerranéennes », Domaine de Saint-Paul, 84914 Avignon, France

e-mail: ivan.scotti@paca.inra.fr 
diversity was found to be impoverished in each clump relative to the global population at about half of the loci.

- Conclusion Overall, our results suggest that forest disturbance has changed the patterns of distribution of genetic diversity, with potential consequences on long-term population viability.

Keywords Tropical rainforest - Amazon - Guiana shield . Demogenetics - Spatial genetic structure · Parentage analysis · Bayesian clustering $\cdot$ Regeneration

\section{Introduction}

Moderate forest disturbances are predicted to have a positive impact on species diversity by allowing the coexistence of species typical of different successional stages. This expectation was formulated by Connell $(1978,1978,1978)$ and was found to be consistent with observational data in a disturbance experiment performed in the Guiana shield (Molino and Sabatier 2001). The same experimental setting was later used to assess the effect of perturbation on the functional diversity of the regenerating forest (Baraloto et al. 2012). This study showed that functional evenness is greater in gaps than in the surrounding undisturbed forest, which agrees with the results on taxonomic diversity by Molino and Sabatier (2001), and detected a marked taxonomic and functional turnover between logged and disturbed portions of the forest. The impact of perturbation on biological diversity can - and should - also be studied at the intra-specific level, because naturally and artificially occurring forest disturbances can have an impact on demography (by increasing or decreasing population growth rates) and on the amount and distribution of genetic diversity in forest tree populations (Ledig 1992).

Disturbances can have a variety of consequences that can affect overall genetic diversity or specifically modify patterns of neutral or adaptive genetic diversity (Banks et al. 2013). Therefore, disturbance-driven demo-genetic processes, and the patterns they produce, can ultimately have a long-term impact on population viability (Collevatti and Hay 2011). Intermediate disturbance (defined here as "having intermediate intensity" following Fox (2013) and citations therein) occurs at localised geographical scales. In such cases, population dynamics can be altered due to modifications of the ecological conditions in which the regeneration occurs, even if most of the adult populations existing at the time of disturbance is left untouched; note that this is different from processes taking place in the case of selective logging, forest management or forest fragmentation, which alter directly reproductive population demography and mating system (White et al. 2002; Lowe et al. 2005; Ratnam et al. 2014). The effect of canopy gaps on genetic diversity and spatial genetic structure of tree populations has been studied in cases in which stand history allowed the identification of cohorts derived from regeneration under forest cover and in gaps or at forest margins. Examples are known from the conifers Picea abies (Pinaceae) (Scotti et al. 2008; Piotti et al. 2009) and Pinus clausa (Pinaceae) (Parker et al. 2001), in the shrub Camellia japonica (Theaceae) (Ueno et al. 2006), in the Neotropical pioneer Cecropia obtusifolia (Cecropiaceae) (Epperson and AlvarezBuylla 1997) and from the Neotropical palm Iriartea deltoidea (Arecaceae) (Sezen et al. 2005, 2007). The general message that can be drawn from these case studies is that postdisturbance cohorts have shallower spatial genetic structure, skewed reproductive contribution from nearby adult trees and reduced diversity, relative to their undisturbed counterparts. Unfortunately, these measures of genetic diversity were not matched by assessments of community-level effects of disturbance, and therefore, it is not possible to tell whether changes in genetic structure are associated to similar - or divergentmodifications in community structure. In the present studyas well as in a companion paper on a different tree species, Virola michelii (Montaigne et al. Unpublished) - we describe the study of the impact of intermediate forest disturbance on genetic diversity in the same plots that were studied, at the community level, by Molino and Sabatier (2001) and Baraloto et al. (2012). We can therefore test whether the intermediate disturbance hypothesis may hold at the intra-specific level for two different species, in a context where it has been proven valid at the community level.

The study species presented here, Jacaranda copaia (Aubl.) D. Don is a light-demanding species whose seeds show little or no dormancy (Jones et al. 2005). Therefore, in the case of a sudden expansion of the surface available for the establishment of its seedlings after a forest disturbance, an instantaneous demographic burst in young age classes is expected and is indeed observed in our experimental system. However, the genetic consequences of such an abrupt transition are unknown. Even if $J$. copaia seeds are wind dispersed, the dispersal curve has a high peak centred on the maternal tree (Jones et al. 2005) and therefore one can predict that, when large canopy gaps are (artificially) opened, the offspring of the closest fruiting trees will be over-represented among the newly established saplings in a given gap. The consequence of this should be enhanced spatial genetic structure and locally depressed genetic diversity in the regeneration taking place in post-disturbance canopy gaps, due to increased genetic relatedness of local pools of saplings. We discuss our results in light of this hypothesis, of the results previously obtained in the same system at the community level, which favour the intermediate disturbance hypothesis, and of the available literature on post-disturbance levels of genetic diversity. 


\section{Materials and methods}

One hundred and twenty-eight mature trees and 611 juvenile stems ( $<10 \mathrm{~cm}$ d.b.h.) were sampled in 2006 and geo-localised in a 25-ha area, which belongs to the Paracou long-term forest survey site (Paracou, French Guiana) (Gourlet-Fleury et al. 2004) and has undergone experimental disturbance in 1986. For the experiment, the area was subdivided in four plots, of which one was left aside as a control, and the other three were submitted to different levels of disturbance, which resulted in gaps of increasing size and an increasing overall disturbed area (Fig. 1 and Table 1). The position of canopy gaps and forest disturbances was recorded immediately after the experiment, and the position of juveniles relative to canopy gaps was recorded at the time of sampling and used for subsequent analyses. The samples were subdivided into three groups: adult trees, saplings growing in canopy gaps $(N=449)$, and saplings growing under forest cover $(N=112)$.

DNA was extracted from cambium or leaves according to the method developed by Colpaert et al. (2005). Each sample was characterised at nine simple sequence repeat (SSR) nuclear loci (Jones and Hubbell 2003; Barthe et al. 2012; ScottiSaintagne et al. 2013) (see Table 2 for marker names and the above references for marker description). The genotype and geo-localisation data were used to run spatial genetic structure and genetic relatedness analyses. Data handling, re-sampling, basic data analyses and plotting were performed with ad hoc $\mathrm{R}$ (R Development Core Team 2008) scripts (available from the authors under request). To compare diversity levels in data sets with different sample sizes, a re-sampling procedure inspired from the RaBoT method (Scotti et al. 2013) was applied: for each locus and each population pair, the largest population was re-sampled (with replacement) 1,000 times (with sample size equal to the size of the smaller population); diversity was computed for each subsample; and the distribution of these bootstrapped diversity values was compared to the empirical diversity value obtained from the smaller population. Large departures of the smaller population's empirical diversity value from the median of the bootstrapped values, obtained from subsamples of the larger population, were taken as suggestive of true diversity differences between the two populations. Analyses of spatial autocorrelation of relatedness coefficients were performed with the SPAGeDi program (Hardy and Vekemans 2002) with adult allele frequencies as reference, on the three subsamples defined above (adults, saplings in canopy gaps, saplings under forest cover), using $F_{i j}$ (Loiselle et al. 1995) as a genetic relatedness statistic. Geographic distance intervals were set at 20, 40, 60, 80, 100, 200, $300,400,500$ and $750 \mathrm{~m}$; intervals were denser at shorter distances to closely inspect structures in clumps of saplings.

Fig. 1 Study area and sampling. Each forest inventory plot (numbered 9 through 12) has a 250-m-wide square inner area and a 20-m-wide buffer zone. Grey contours: canopy gaps. Black circles: adult trees. Dark grey circles: saplings sampled in canopy gaps. Light grey circles: saplings sampled under forest cover. Map North is above

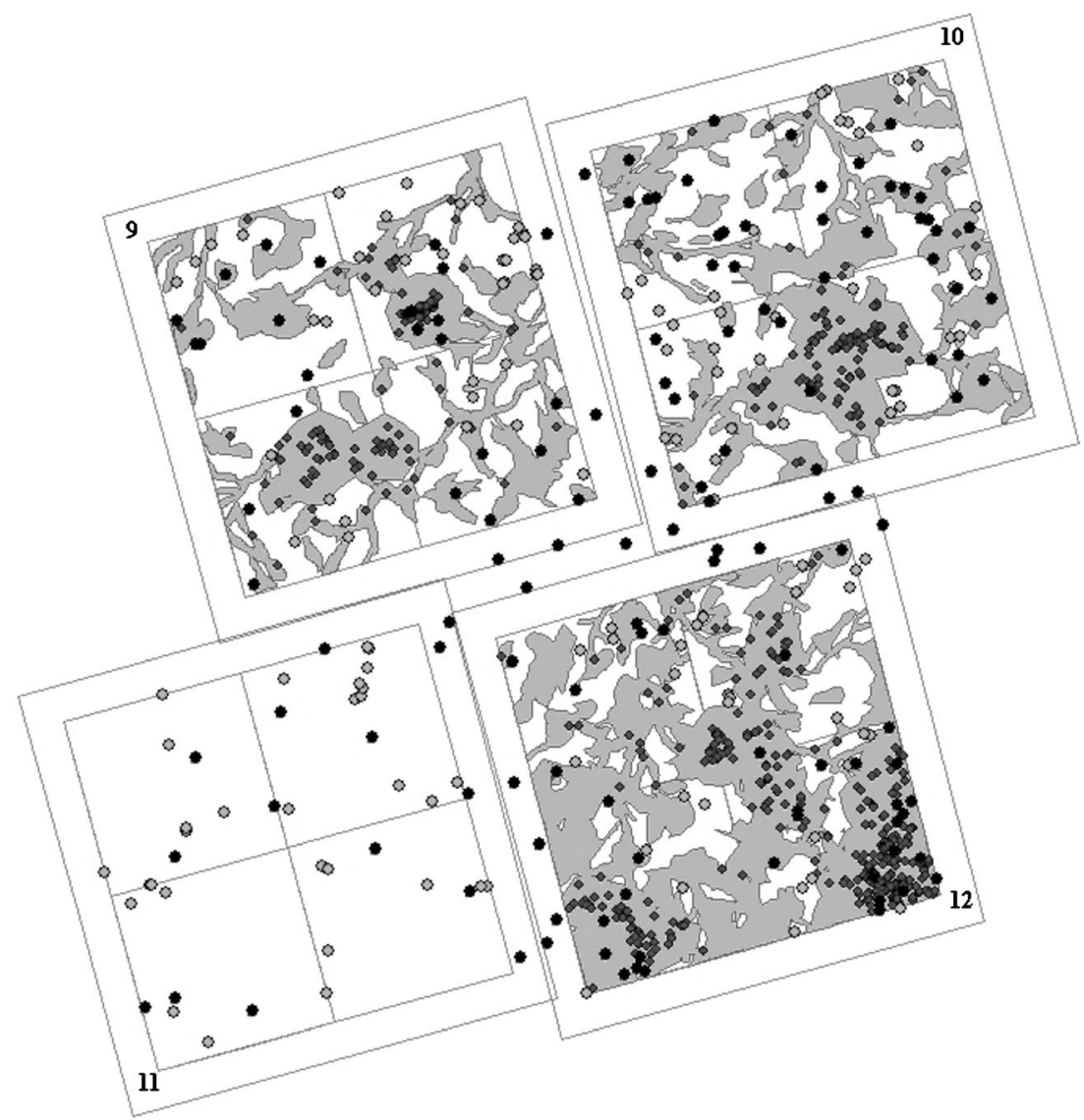


Table 1 Proportion of canopy gap and forest cover surfaces, and stem density (in individuals/ha), in the sampled plots

\begin{tabular}{|c|c|c|c|c|c|c|c|}
\hline \multirow[t]{2}{*}{ Plot } & \multirow{2}{*}{$\begin{array}{l}\text { Forest gap surface }(\%) \\
\text { Gap }\end{array}$} & \multicolumn{3}{|c|}{ Stem density } & \multicolumn{3}{|c|}{ Stem numbers } \\
\hline & & Ad & Gap & Control & $\mathrm{Ad}$ & Gap & Control \\
\hline 11 & 0 & 1.8 & 0 & 5 & 11 & 0 & 31 \\
\hline 9 & 39.6 & 3.9 & 45.9 & 9.8 & 21 & 113 & 37 \\
\hline 10 & 46.5 & 6.7 & 43.1 & 10.5 & 42 & 125 & 35 \\
\hline 12 & 68.4 & 5.8 & 80.7 & 14.7 & 36 & 344 & 29 \\
\hline
\end{tabular}

$A d$ adult trees, Gap saplings growing in canopy gaps, Control saplings growing outside canopy gaps

Statistical significance was assessed by 1,000 permutations. The same analyses were also performed separately for juveniles in each of the four plots, with distances restricted to $400 \mathrm{~m}$. For the comparison of results obtained from juveniles inside and outside canopy gaps, ten random subsamples from the former data set, having the same sample size as the latter, were drawn and analysed. The bundle of individual autocorrelation values from these ten data sets was compared to the results obtained on full data sets.

Automated Bayesian assignment was used to infer clusters of genetically related juveniles. The analysis was performed through the algorithm implemented in STRUCTURE (Pritchard et al. 2000). Ten runs were performed for each value $K$ between 1 and 20 for the number of groups. The most likely $K$ value was inferred by the ad hoc method developed by Evanno et al. (2005). The admixture model was applied. The threshold to assign individuals to a cluster was set to $Q=$
0.8. CLUMPP (Jakobsson and Rosenberg 2007) and DISTRU CT (Rosenberg 2004) were used to summarise and display results obtained with STRUCTURE. Significance of the divergence between clusters was tested by an exact $G$ test as implemented in Genepop 4.2 (Raymond and Rousset 1995; Rousset 2008). Departures from random spatial distribution of individuals belonging to each cluster were tested, at the plot level, by applying a chi-square test to the numbers of individuals of a given cluster in each plot, against the expectation that they should be proportional to the overall numbers of individuals mapped in each plot; these tests were performed in R ( R Development Core Team 2008).

\section{Results}

Levels of diversity were similar in adults and juveniles, both from canopy gaps and from undisturbed areas (Table 2); a general trend towards homozygote excess was observed in all cohorts. In contrast, the spatial distribution of relatedness coefficients showed divergent patterns in canopy gap and forest cover juvenile groups. For the gap group, kinship coefficient $F_{i j}$ showed positive and significant values up to around $80 \mathrm{~m}$ and negative and significant values above $100 \mathrm{~m}$ (Fig. 2a); in contrast, for the forest cover saplings, positive values lost significance at around $50 \mathrm{~m}$, without any significant values thereafter (Fig. 2b). The adult group showed a somehow intermediate situation (Fig. 2c). Autocorrelogram slope values were similar for all groups and all negative and significant (Table 3). Note, however, that allele frequencies in

Table 2 Genetic diversity

\begin{tabular}{|c|c|c|c|c|c|c|c|c|c|c|c|c|c|c|c|c|c|c|}
\hline \multirow[t]{2}{*}{ Locus } & \multicolumn{6}{|l|}{$\mathrm{Ad}$} & \multicolumn{6}{|l|}{ Gap } & \multicolumn{6}{|c|}{ Control } \\
\hline & $N$ & $A$ & $A_{\mathrm{e}}$ & $H_{\mathrm{o}}$ & $H_{\mathrm{e}}$ & $F_{\text {IS }}$ & $N$ & $A$ & $A_{\mathrm{e}}$ & $H_{\mathrm{o}}$ & $H_{\mathrm{e}}$ & $F_{\text {IS }}$ & $N$ & $A$ & $A_{\mathrm{e}}$ & $H_{\mathrm{o}}$ & $H_{\mathrm{e}}$ & $F_{\text {IS }}$ \\
\hline JACC1_1 & 77 & 11 & 1.4 & 0.24 & 0.26 & 0.08 & 401 & 12 & 1.2 & 0.17 & 0.17 & 0.00 & 89 & 7 & 1.3 & 0.22 & 0.20 & -0.10 \\
\hline JACC2 & 64 & 34 & 22.7 & 0.86 & 0.96 & 0.10 & 365 & 39 & 17.3 & 0.87 & 0.94 & 0.07 & 69 & 29 & 17.0 & 0.79 & 0.94 & 0.16 \\
\hline JACC21 & 79 & 12 & 2.9 & 0.55 & 0.65 & 0.15 & 429 & 16 & 2.7 & 0.56 & 0.63 & 0.11 & 87 & 13 & 2.8 & 0.42 & 0.65 & 0.35 \\
\hline JACC22 & 68 & 12 & 4.9 & 0.76 & 0.79 & 0.04 & 407 & 23 & 6.0 & 0.84 & 0.83 & -0.01 & 84 & 13 & 4.7 & 0.79 & 0.79 & 0.00 \\
\hline Jc3A10 & 67 & 12 & 7.0 & 0.86 & 0.63 & 0.27 & 398 & 19 & 5.7 & 0.70 & 0.82 & 0.15 & 93 & 17 & 6.8 & 0.80 & 0.85 & 0.07 \\
\hline Jc3C5 & 65 & 11 & 4.6 & 0.78 & 0.77 & 0.02 & 440 & 15 & 5.9 & 0.83 & 0.83 & 0.01 & 102 & 14 & 4.9 & 0.79 & 0.80 & 0.00 \\
\hline Jc3F11 & 72 & 34 & 12.1 & 0.92 & 0.83 & 0.09 & 413 & 43 & 11.3 & 0.78 & 0.91 & 0.14 & 91 & 31 & 10.4 & 0.84 & 0.90 & 0.08 \\
\hline $\mathrm{Jc} 3 \mathrm{~F} 4$ & 74 & 19 & 8.2 & 0.88 & 0.81 & 0.08 & 413 & 27 & 7.6 & 0.82 & 0.87 & 0.06 & 99 & 21 & 9.0 & 0.79 & 0.89 & 0.11 \\
\hline Jc3H10 & 85 & 24 & 14.9 & 0.93 & 0.82 & 0.12 & 448 & 27 & 16.1 & 0.84 & 0.94 & 0.10 & 101 & 22 & 14.3 & 0.79 & 0.93 & 0.15 \\
\hline Mean & & 18.8 & 8.7 & 0.75 & 0.72 & 0.11 & & 24.5 & 8.2 & 0.71 & 0.77 & 0.07 & & 18.6 & 7.9 & 0.69 & 0.77 & 0.09 \\
\hline St. dev. & & 9.7 & 6.8 & 0.22 & 0.20 & 0.07 & & 10.7 & 5.6 & 0.22 & 0.24 & 0.06 & & 7.9 & 5.3 & 0.22 & 0.23 & 0.13 \\
\hline L95 & & -0.2 & -4.5 & 0.31 & 0.33 & -0.04 & & 3.6 & -2.8 & 0.27 & 0.29 & -0.05 & & 3.1 & -2.4 & 0.27 & 0.32 & -0.16 \\
\hline U95 & & 37.7 & 22.0 & 1.19 & 1.12 & 0.25 & & 45.5 & 19.1 & 1.15 & 1.25 & 0.19 & & 34.0 & 18.2 & 1.12 & 1.23 & 0.34 \\
\hline
\end{tabular}

$N$ number of genotyped individuals, $A$ number of alleles, $A_{\mathrm{e}}$ effective number of alleles, $H_{\mathrm{o}}$ observed heterozygosity, $H_{\mathrm{e}}$ expected heterozygosity, $F_{\mathrm{IS}}$ heterozygote deficit, $A d$ adults, Gap saplings growing in canopy gaps, Control saplings growing outside canopy gaps, L95 lower margin of the $95 \%$ confidence interval, $U 95$ upper margin of the $95 \%$ confidence interval 
the adult population were taken as reference for all analyses and that therefore the interpretation of $F_{i j}$ values (as kinship relative to the parent populations) is not the same for saplings and adults. Comparisons among plots corroborate the trend observed in the comparison between forest cover and gap saplings. Figure 3 shows slope (Sp) values for each plot, and Supplementary Fig. 1 shows the corresponding autocorrelograms. There is a qualitative and quantitative difference between the control plot (P11), on one hand, and the three disturbance plots that mimics the differences in pattern between the forest cover and the disturbance seedling populations. To test whether the differences observed between the two juvenile groups may be due to differences in sample size

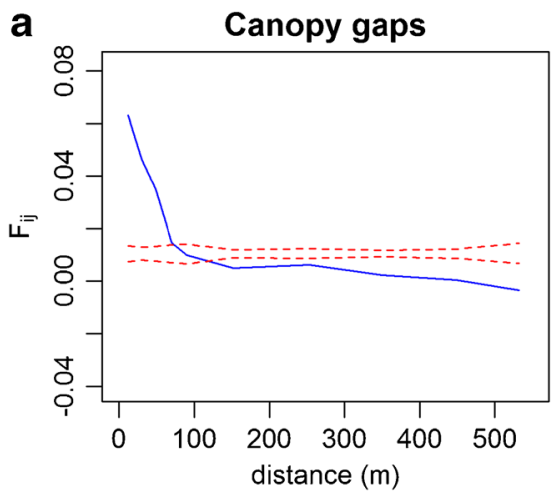

b

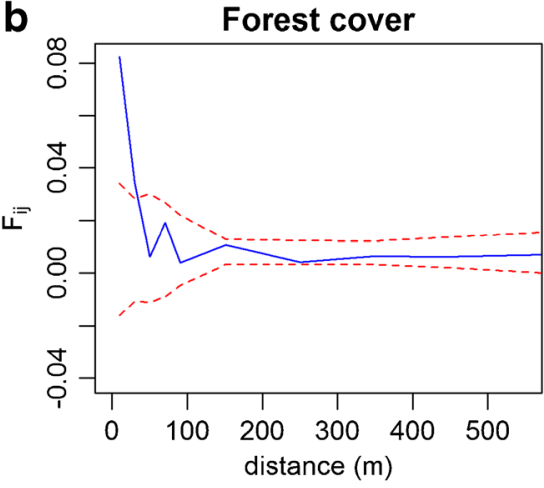

C

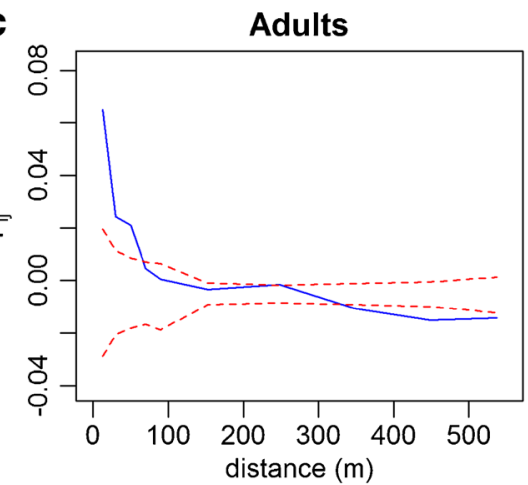

Fig. 2 Spatial autocorrelograms for Loiselle et al. (1995) kinship coefficient $\left(F_{i j}\right)$. Full line: empirical value; dashed lines: limits of the $95 \%$ bootstrap interval. a Canopy gap saplings. b Forest cover saplings. c Adults
Table 3 Observed autocorrelation curve slopes $(b)$ and their associated permutation-based neutral envelopes for $F_{i j}$ (values are reported for the $\log -\log$ regression)

\begin{tabular}{llll}
\hline Sample & \multicolumn{2}{l}{ Slope } & \\
\cline { 2 - 4 } & Observed & \multicolumn{2}{l}{ Neutral envelope } \\
\cline { 3 - 4 } & & Min & Max \\
\hline Canopy gap & $-0.015^{*}$ & -0.00070 & 0.00069 \\
Forest cover & $-0.0083^{*}$ & -0.0037 & 0.0036 \\
Adults & $-0.013^{*}$ & -0.0030 & 0.0028 \\
\hline
\end{tabular}

$* P<0.0001$, significant

$\left(N_{\text {gap }}=449, N_{\text {control }}=112\right)$, the same analyses were run on ten sets of 112 seedlings, randomly chosen from the "gap" dataset, that is, analyses were run on samples from the gap dataset, but with the same sample size as the forest cover dataset. Supplementary Fig. 2 shows autocorrelation plots for the ten subsamples along with the curves obtained for each full data set (same as in Fig. 2). Correlograms for subsamples fluctuate around the full canopy gap data sets and remain distinct from the forest cover curve, indicating that the differences observed between canopy gap and forest cover populations are not due to differences in demographic (sample) size.

The genotypes of both canopy gap and forest cover data sets were submitted to an automated Bayesian assignment procedure to identify groups of closely related genotypes in the juvenile population. The analysis identified two groups $(K=2)$ as the most likely subdivision, according to the likelihood trend and to the Evanno et al. (2005) test (Supplementary Fig. 3). Individuals were then assigned to one or the other genetic cluster when their probability $(Q)$ of assignment to a given group was higher than 0.8 . The divergence between the two clusters

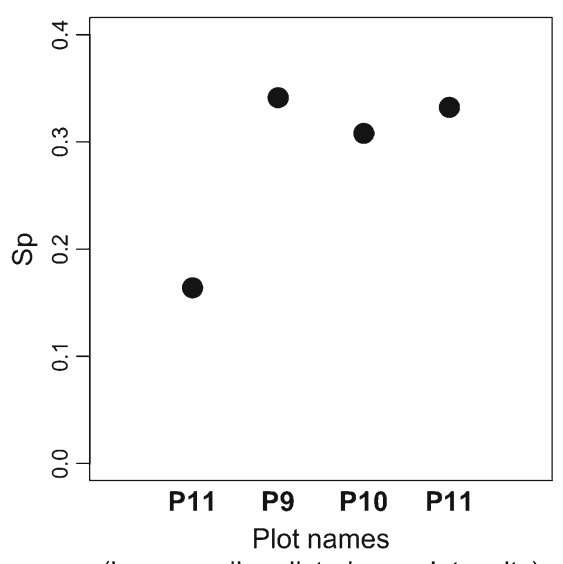

(by ascending disturbance intensity)

Fig. 3 Sp (slope) values of autocorrelograms for each plot. P11: control plot. $P 9, P 10, P 12$ : disturbance plots in ascending order of disturbance intensity 
is $F_{\mathrm{ST}}=0.05$, highly significant according to the exact $G$ test (chi-square $>10^{10}, P$ value $=0$ ). The distribution of both clusters (cluster $1 N=171$ and cluster $2 N=246$; Fig. 4) showed departures from random spatial distribution at the plot level (for cluster 1, chi-square $=29.5, d f=3$, $P$ value $=1.8^{\circ} 10^{-6}$; for cluster $2, X$-squared $=63.9, d f=3, P$ value $=8.5^{\circ} 10^{-14}$ ). The two clusters were submitted to further Bayesian assignment analyses. Neither cluster showed a further structure, with fluctuating $\operatorname{Ln}(\mathrm{K})$ values and no pattern in the delta $K$ values (not shown).

Genetic diversity within each cluster was inspected and compared to the average genetic diversity observed in the global population. Supplementary Fig. 4a, b shows the result of the permutation tests for each cluster and for each locus. For the two clusters, respectively, seven and four loci (out of nine) showed a level of diversity lower than in the global population for an empirical significance level $\alpha=0.05$, and cluster 2 had one locus (locus 6) with a higher diversity than in the bootstrapped samples from the global population. Diversity was also compared with the same method between gap and control cohorts. The trend is much less clear here, with the gap cohort being less diverse at two loci, and more diverse at one locus (Supplementary Fig. 4c).

\section{Discussion}

Our results show that the spatial genetic structure of juvenile cohorts of $J$. copaia is influenced by perturbations. Several pieces of evidence lead us to think that the genetic structure of juvenile cohorts growing after disturbance is different than in juveniles from "background" regeneration under forest cover.

Demography is clearly different, with much denser populations in post-perturbation areas than in the undisturbed parts of the stand (Table 1). This is barely surprising, as J. copaia is a light-sensitive species that readily responds to canopy gaps (Jones et al. 2005). It is thus highly likely that most of the saplings growing in perturbed areas have appeared after the disturbance, while saplings in the control areas are likely to be the outcome of sporadic seedling establishment in small, natural gaps and may have appeared over a much longer time span (wood rings are notoriously rare or absent in tropical rainforest trees, and although rings appear in Jacaranda cores, they are nevertheless hard to interpret and unreliable as indicators of sapling age, so this method could not be applied to determine sapling age). The structure of the two populations is likely to differ because of such differences in establishment rates, but accelerated

Fig. 4 Spatial distribution of genetic clusters inferred by automated Bayesian assignment. Background map is the same as in Fig. 1. White dots: cluster 1; black dots: cluster 2

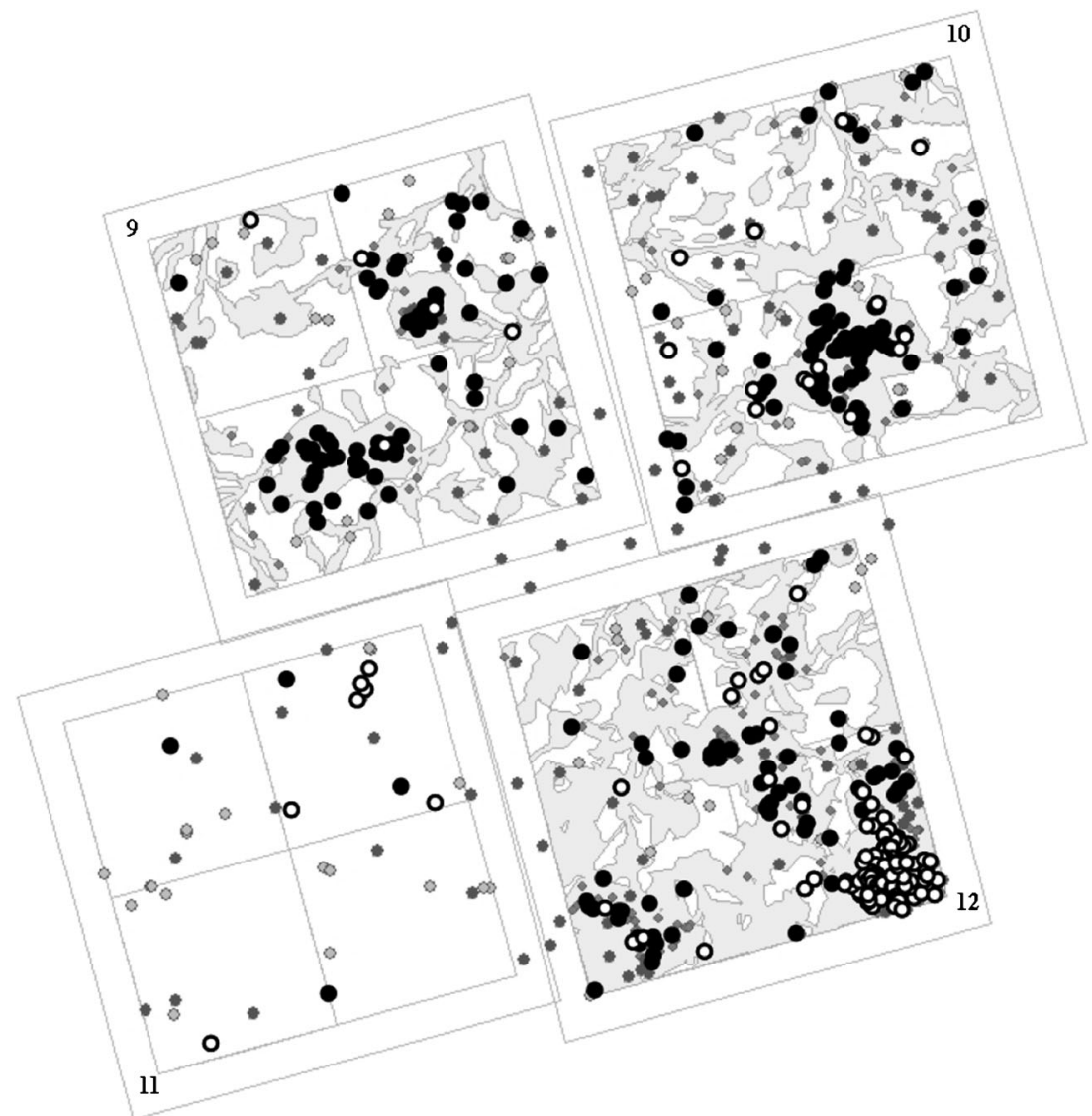


demography is a component - and perhaps the most important one - of the very disturbance effects we intended to study. Zones of high seedling density are not strictly limited to canopy gaps; however, it has to be noted that direct and indirect disturbance extends beyond canopy gaps and that even the creation of forest paths between and around gaps can subtly but detectably change ecological conditions and favour the growth of light-demanding species. Whereas genetic relatedness is relatively evenly distributed in space for natural regeneration juveniles (except at very short distances), there is a clear inverse relationship between relatedness and spatial distance in post-disturbance cohorts, as shown by autocorrelation analyses (Fig. 2). The same trend was detected in the comparison between control and disturbance plots (Fig. 3). Relative levels of genetic autocorrelation reported in the present study are similar to those reported for the shorter distance class (for younger, greenhousegrown seedlings) by Jones and Hubbell (2006) in a relatively undisturbed stand. In adults, SGS does not appear to be stronger than in seedlings, contrary to what was reported by Jones and Hubbell (2006), and does not extend farther than $100 \mathrm{~m}$, whereas for the same site, a larger geographical study reported positive autocorrelation beyond $1,000 \mathrm{~m}$ (Hardy et al. 2006); divergence with the latter study may be due to differences in the sampling strategy and perhaps in the markers used. High mortality rates between the sapling and the mature stages may also erase the strong structure observed here for saplings; their SGS patterns may therefore, on the long run, converge on the structure observed in adults. Although absolute values do not differ, relatedness is above average over longer distances in canopy gap than in forest cover saplings and is consistently below average at larger distances in the former but not in the latter. The observed relatedness distribution means that, in postdisturbance cohorts, patches of related genotypes are larger and that, if this structure is maintained at the adult stage, there is a risk of increased bi-parental inbreeding for the next generation. This may be particularly true as Jacaranda is insect-pollinated, and pollinators may easily transfer pollen between neighbouring trees, if given the opportunity to do so by the clumped distribution of stems observed here. The uneven spatial distribution of genetic relatedness is even more sharply highlighted by automated Bayesian assignment analyses, which grouped juvenile genotypes in at least two spatially clumped genetic clusters. The strength of the observed spatial clustering is such that one could easily consider that the juvenile population is composed of at least two genetically distinct subpopulations (divergence is of $5 \%$, comparable to what is currently observed between populations). Because the genetic clusters have a spatially clumped, non-overlapping distribution centred on major canopy gaps, we suggest that the abrupt demographic transition caused by perturbation has a dramatic effect on the population's genetic structure. Moreover, as shown by the genetic diversity results, each of these spatially clumped groups has a lower diversity than an equally sized random draw from the global population (Supplementary Fig. 4). Thus, the increased relatedness of same cluster samples is - not surprisingly - associated with reduced levels of genetic diversity within cluster. Such trends recall those found in other pioneer species, where "reproductive dominance" of few trees and reduced genetic diversity have been observed in second-growth forests (Aldrich and Hamrick 1998; Sezen et al. 2005) or in extremely canopy gap-dependent species such as Cecropia (Epperson and Alvarez-Buylla 1997), but contrast with other studies on long-lived tropical pioneer species (Born et al. 2008a, b). The general picture emerging from these results is that canopy gaps induced an increase in juvenile census size and that this demographic increase is associated to locally reduced levels of genetic diversity, through local clumping of genetically related seedlings. The overall picture is in agreement with most studies of genetic diversity in post-disturbance seedling cohorts, which show loss of diversity and over-dominance of few reproductive trees (Sezen et al. 2007; Piotti et al. 2009). Loss of SGS in disturbance gaps is not observed here as it was in other studies (Sezen et al. 2005; Scotti et al. 2008), and on the contrary, gap-dwelling cohorts have distinctly negative autocorrelation at longer distances. At the gap scale, genetic diversity is lower than in equivalent cohorts growing in undisturbed areas. This contrasts with the pattern observed at the community level (Molino and Sabatier 2001; Baraloto et al. 2012), which is in agreement with the Intermediate Disturbance Hypothesis IDH (but see Fox (2013) for an empirical and theoretical rebuttal of IDH). Therefore, the intermediate disturbance hypothesis does not appear to hold at the intra-specific level for $J$. copaia, whereas it is validated at the community level.

\section{Conclusion}

Artificial disturbance did not affect overall levels of diversity but changed its spatial distribution, with potential consequences on inbreeding levels of subsequent generations. In this case, increased demographic size actually entails local genetic impoverishment, and locally increased species abundance does not necessarily mean sustained genetic viability on the long term.

Acknowledgments We wish to thank Saint-Omer Cazal (INRA) for sample and data collection and Audrey Jolivot and Lilian Blanc (CIRAD) for providing plot and disturbance maps.

Funding The research was funded by the Research program ECOFORBGF "Écosystèmes forestiers". IS was supported by an "Investissement d'Avenir" grant managed by Agence Nationale de la Recherche (CEBA, ref. ANR-10-LABX-0025). 


\section{References}

Aldrich PR, Hamrick JL (1998) Reproductive dominance of pasture trees in a fragmented tropical forest mosaic. Science 281:103-105

Banks SC, Cary GJ, Smith AL et al (2013) How does ecological disturbance influence genetic diversity? Trends Ecol Evol 28:670-679

Baraloto C, Hérault B, Paine CET et al (2012) Contrasting taxonomic and functional responses of a tropical tree community to selective logging. J Appl Ecol 49:861-870

Barthe S, Gugerli F, Barkley NA et al (2012) Always look on both sides: phylogenetic information conveyed by Simple Sequence Repeat allele sequences. PLoS One 7:e40699

Born C, Hardy OJ, Chevallier M-H et al (2008a) Small-scale spatial genetic structure in the Central African rainforest tree species Aucoumea klaineana: a stepwise approach to infer the impact of limited gene dispersal, population history and habitat fragmentation. Mol Ecol 17:2041-2050

Born C, Kjellberg F, Chevallier M-H et al (2008b) Colonization processes and the maintenance of genetic diversity: insights from a pioneer rainforest tree, Aucoumea klaineana. Proc R Soc B Biol Sci 275: 2171-2179

Collevatti RG, Hay JD (2011) Kin structure and genotype-dependent mortality: a study using the Neotropical tree Caryocar brasiliense. J Ecol 99:757-763

Colpaert N, Cavers S, Bandou E et al (2005) Sampling tissue for DNA analysis of trees: trunk cambium as an alternative to canopy leaves. Silvae Genet 54:265-269

Connell JH (1978) Diversity in tropical rain forests and coral reefs. Science 199:1302-1310

R Development Core Team (2008) R: a language and environment for statistical computing.

Epperson BK, Alvarez-Buylla ER (1997) Limited seed dispersal and genetic structure in life stages of Cecropia obtusifolia. Evolution $51: 275-282$

Evanno G, Regnaut S, Goudet J (2005) Detecting the number of clusters of individuals using the software structure: a simulation study. Mol Ecol 14:2611-2620

Fox JW (2013) The intermediate disturbance hypothesis should be abandoned. Trends Ecol Evol 28:86-92

Gourlet-Fleury S, Guehl J-M, Laroussinie O (2004) Ecology \& management of a neotropical rainforest. Lessons drawn from Paracou, a long-term experimental research site in French Guiana. Elsevier, Paris

Hardy OJ, Maggia L, Bandou E et al (2006) Fine-scale genetic structure and gene dispersal inferences in 10 Neotropical tree species. Mol Ecol 15:559-571

Jakobsson M, Rosenberg NA (2007) CLUMPP: a cluster matching and permutation program for dealing with label switching and multimodality in analysis of population structure. Bioinformatics 23:1801-1806

Jones FA, Hubbell SP (2003) Isolation and characterisation of microsatellite loci in the tropical tree Jacaranda copaia (Bignoniaceae). Mol Ecol Notes 3:403-405

Jones FA, Hubbell SP (2006) Demographic spatial genetic structure of the Neotropical tree, Jacaranda copaia. Mol Ecol 15:3205-3217
Jones FA, Chen J, Weng G-J et al (2005) A genetic evaluation of seed dispersal in the neotropical tree Jacaranda copaia (Bignoniaceae). Am Nat 166:543-555

Ledig FT (1992) Human impacts on genetic diversity in forest ecosystems. Oikos 63:87-108

Loiselle BA, Sork VL, Nason JD, Graham C (1995) Spatial genetic structure of a tropical understory shrub, Psychotria officinalis (Rubiaceae). Am J Bot 82:1420-1425

Lowe AJ, Boshier DH, Ward M, et al (2005) Genetic resource impacts of habitat loss and degradation; reconciling empirical evidence and predicted theory for Neotropical trees. Heredity 95:255-273

Molino J-F, Sabatier D (2001) Tree diversity in tropical rain forests: a validation of the intermediate disturbance hypothesis. Science 294: $1702-1704$

Parker KC, Hamrick JL, Parker AJ, Nason JD (2001) Fine-scale genetic structure in Pinus clausa (Pinaceae) populations: effects of disturbance history. Heredity 87:99-113

Piotti A, Leonardi S, Piovani P et al (2009) Spruce colonization at treeline: where do those seeds come from? Heredity 103:136-145

Pritchard JK, Stephens M, Donnelly P (2000) Inference of population structure using multilocus genotype data. Genetics 155:945-959

Ratnam W, Rajora OP, Finkeldey R, et al (2014) Genetic effects of forest management practices: Global synthesis and perspectives. For Ecol Manage 33:52-65

Raymond M, Rousset F (1995) GENEPOP (version 1.2): population genetics software for exact tests and ecumenicism. J Hered 86 : 248-249

Rosenberg NA (2004) Distruct: a program for the graphical display of population structure. Mol Ecol Notes 4:137-138

Rousset F (2008) genepop'007: a complete re-implementation of the genepop software for Windows and Linux. Mol Ecol Resour 8: 103-106

Scotti I, Gugerli F, Pastorelli R et al (2008) Maternally and paternally inherited molecular markers elucidate population patterns and inferred dispersal processes on a small scale within a subalpine stand of Norway spruce (Picea abies [L.] Karst.). For Ecol Manag 255: 3806-3812

Scotti I, Montaigne W, Cseke K, Traissac S (2013) RaBoT: a rarefactionby-bootstrap method to compare genome-wide levels of genetic diversity. Ann For Sci 70:631-635

Scotti-Saintagne C, Dick CW, Caron H et al (2013) Amazon diversification and cross-Andean dispersal of the widespread Neotropical tree species Jacaranda copaia (Bignoniaceae). J Biogeogr 40:707-719

Sezen UU, Chazdon RL, Holsinger KE (2005) Genetic consequences of tropical second-growth forest regeneration. Science 307:891

Sezen UU, Chazdon RL, Holsinger KE (2007) Multigenerational genetic analysis of tropical secondary regeneration in a canopy palm. Ecology 88:3065-3075

Ueno S, Tomaru N, Yoshimaru H et al (2006) Effects of canopy gaps on the genetic structure of Camellia japonica saplings in a Japanese old-growth evergreen forest. Heredity 96:304-310

White GM, Boshier DH, Powell W (2002) Increased pollen flow counteracts fragmentation in a tropical dry forest: an example from Swietenia humilis Zuccarini. Proc Natl Acad Sci U S A 99:20382042 